\title{
ERRATA
}

\section{Pharmacokinetics of Intravenous Cefetamet and Oral Cefetamet Pivoxil in Children}

\author{
WILLIAM L. HAYTON, ROLF A. WALSTAD, ELSE THURMANN-NIELSEN, TORBJøRN KUFAAS, \\ JOHANNES KNEER, REINHARD J. AMBROS, HANS E. RUGSTAD, EIRIK MONN, \\ EGIL BODD, AND KLAUS STOECKEL \\ College of Pharmacy, The Ohio State University, Columbus, Ohio 43210-1291; Department of Pharmacology \\ and Toxicology and Department of Pediatric Surgery, University of Trondheim, 7030 Trondheim, \\ and Rikshospitalet, 0027 Oslo 1, Norway; and Pharmacokinetics, Department of \\ Clinical Research, F. Hoffmann-La Roche Ltd, CH-4002 Basel, Switzerland
}

Volume 35 , no. 4 , p. 720 , line 14 of the abstract: " $49.3 \% \pm 15.7 \%$ " should read " $46.6 \% \pm 14.1 \%$."

Page 720 , line 15 of the abstract: " $37.9 \% \pm 10.0 \%$ " should read " $42.0 \pm 4.46$."

Page 722, column 2, lines 13 and $14:$ " $38.1 \% \pm 8.92 \%$ and $29.9 \% \pm 7.40 \%$ " should read " $36.3 \% \pm 7.48 \%$ and $33.1 \% \pm$ 2.6\%."

Page 723, Table 3, column 8, row 10: "5.2 \pm 0.98 " should read " $5.02 \pm 0.93$."

Page 723, Table 3, column 9, row 10: “ $38.1 \pm 8.92$ ”" should read " $36.3 \pm 7.48$."

Page 723, Table 3, column 9, row 15: “29.9 \pm 7.4” should read " $33.1 \pm 2.6$."

Page 723, Table 3, column 10, row 6: "41.1" should read "41.4."

Page 723, Table 3, column 10, row 10: “49.3 \pm 15.7 ” should read " $46.6 \pm 14.1$."

Page 723, Table 3, column 10, row 15: “37.9 \pm 10.0 " should read " $42.0 \pm 4.46$."

Page 723, column 2, line 6: “ $0.422 \pm 0.132$ and $0.618 \pm 0.066$ " should read " $0.324 \pm 0.067$ and $0.309 \pm 0.112$."

\section{Detection of Extended-Spectrum $\beta$-Lactamases in Members of the Family Enterobacteriaceae: Comparison of the Double-Disk and Three-Dimensional Tests}

KENNETH S. THOMSON AND CHRISTINE C. SANDERS

Creighton University School of Medicine, Omaha, Nebraska 68178

Volume 36, no. 9, p. 1879: Table 2 should appear as shown below:

\begin{tabular}{|c|c|c|c|c|c|c|c|c|c|c|c|c|c|c|c|c|c|c|c|c|}
\hline \multirow[b]{2}{*}{ Antibiotic } & \multicolumn{4}{|c|}{ Non-ES $\beta$-producing controls } & \multicolumn{16}{|c|}{ ES $\beta$ producers } \\
\hline & $\begin{array}{c}\text { No } \\
\text { enzyme }^{b}\end{array}$ & $\underset{1}{\text { TEM- }}$ & $\underset{2}{\text { TEM- }}$ & $\underset{1}{\text { SHV- }}$ & $\underset{3}{\text { TEM- }}$ & $\underset{4}{\text { TEM- }}$ & $\underset{5}{\text { TEM- }}$ & $\underset{7}{\text { TEM- }}$ & $\underset{8}{\text { TEM- }}$ & $\underset{9}{\text { TEM- }}$ & $\underset{10}{\text { TEM- }}$ & $\underset{12}{\text { TEM- }}$ & $\underset{101}{\text { TEM- }}$ & $\underset{2}{\text { SHV- }}$ & $\underset{3}{\text { SHV- }}$ & $\mathrm{SHV}_{4}$ & $\underset{5}{\text { SHV- }}$ & $\underset{2}{\text { CAZ- }}$ & $\underset{1}{\text { MIR- }}$ & $\begin{array}{l}\text { Enzyme } \\
\text { with pI } \\
\text { of } 5.95\end{array}$ \\
\hline Cefotaxime & - & - & - & - & + & + & + & + & + & + & + & - & + & + & + & + & + & + & + & + \\
\hline Ceftriaxone & - & - & - & - & + & + & + & + & + & + & + & - & + & + & + & + & + & + & + & + \\
\hline Ceftazidime & - & - & - & - & - & - & - & - & - & - & - & - & - & - & - & - & - & - & - & - \\
\hline Aztreonam & - & - & - & - & - & - & - & - & - & - & - & - & - & - & - & - & - & - & - & - \\
\hline Cefoxitin & - & - & - & - & - & - & - & - & - & - & - & - & - & - & - & - & - & - & + & - \\
\hline $\begin{array}{l}\text { Cefopera- } \\
\text { zone }\end{array}$ & - & - & + & + & + & + & + & + & + & + & + & + & + & + & + & + & + & + & + & + \\
\hline $\begin{array}{l}\text { Cefaman- } \\
\text { dole }\end{array}$ & - & + & + & + & + & + & + & + & + & + & + & + & + & + & + & + & + & + & + & + \\
\hline Piperacillin & - & + & + & + & + & + & + & + & + & + & + & + & + & + & + & + & + & + & + & + \\
\hline
\end{tabular}

